\title{
HIV prevalence, related risk behaviors, and correlates of HIV infection among people who use drugs in Cambodia
}

\author{
Heng Sopheab ${ }^{1 *}$, Chhorvann Chhea', Sovannary Tuot $^{2}$ and Jonathan A. Muir ${ }^{3}$
}

\begin{abstract}
Background: Although HIV prevalence in Cambodia has declined to $0.6 \%$ among the general population, the prevalence remains high among female sex workers (14.0\%) and men who have sex with men (2.3\%). Over the past 10 years, the number of people who use drugs (PWUDs) has increased considerably. PWUDs, especially people who inject drugs (PWIDs), who have multiple sex partners or unprotected sex contribute to a higher HIV prevalence. This paper aims to estimate the prevalence of HIV across PWUD groups and to identify factors associated with HIV infection.

Methods: Respondent-driven sampling (RDS) was used to recruit 1626 consenting PWUDs in 9 provinces in 2012. Questionnaires and blood specimens were collected. HIV prevalence estimates were calculated using RDSAT 7.1. Individual weightings for HIV were generated with RDSAT and used for a weighted analysis in STATA 13. Multivariate logistic regression was used to identify the independent factors associated with HIV prevalence.

Results: Most of the PWUDs were men (82.0\%), and 7.3\% were PWIDs. Non-PWIDs, especially users of amphetaminetype stimulants (ATS), represented the larger proportion of the participants (81.5\%). The median age for of the PWUDs was 24.0 years (IQR: 20-29). The HIV prevalence among the PWUDs was 5.1\% (95\% Cl: 4.1-6.2), 24.8\%, among PWIDs and $4.0 \%$ among non-PWIDs. The HIV prevalence among female PWIDs was 37.5, and $22.5 \%$ among male PWIDs. Four factors were independently associated with HIV infection: female sex, with AOR $=7.8$ (95\% Cl: 3.00-20.35); age groups 21-29 and older ( $A O R=10.3,95 \% \mathrm{Cl}: 1.2-20.4$ ); and using drugs for $\geq 12$ months ( $A O R=4.0,95 \% \mathrm{Cl}: 1.38-11.35$ ). Finally, injecting drugs remained a strong predictor of HIV infection, with an AOR $=4.1$ (95\% Cl: 1.53-10.96).

Conclusion: HIV prevalence remains high among PWIDs. Harm reduction efforts, such as needle and syringe provision programs, must improve their coverage. Innovative strategies are needed to reach sub-groups of PWUDs, especially women who inject drugs. Furthermore, the large proportion of non-PWIDs, especially ATS users, should not be ignored. Therefore, combined HIV prevention and harm reduction programs should integrate ATS users.
\end{abstract}

Keywords: HIV, People who use drugs, People who inject drugs, PWID, Non-PWID, ATS users, Cambodia

\section{Background}

Over the past 25 years, remarkable progress has been made in the fight against HIV in Cambodia. The HIV prevalence has fallen from $2.0 \%$ (1999) to $0.6 \%$ (2015) among the general population aged 15-49 years [1]. However, a high prevalence is still observed among key populations, such as female sex workers (14.0 to $15.0 \%)$ $[2,3]$ and men who have sex with men $(2.3 \%)[4]$.

\footnotetext{
* Correspondence: hsopheab@niph.org.kh

${ }^{1}$ School of Public Health at the National Institute of Public Health, Lot \#80, Samdech Penn Nouth Blvd. Tuol Kork District, Phnom Penh, Cambodia Full list of author information is available at the end of the article
}

Since 2004, evidence has indicated an increase in the number of people who use drugs (PWUD) and the availability of illicit drugs in Cambodia. The country has changed from a drug trafficking transit location to a site of drug production and use $[5,6]$. The country has been affected by illicit drug abuse problems, mainly amphetamine-type stimulant (ATS) use. Notable increases have been observed among youth and sex workers. A study among youth out of school in 2010 showed that approximately $4 \%$ of young women and $15 \%$ of young men aged 10 to 24 years reported ever having used drugs [7].

(C) The Author(s). 2018 Open Access This article is distributed under the terms of the Creative Commons Attribution 4.0 International License (http://creativecommons.org/licenses/by/4.0/), which permits unrestricted use, distribution, and 
PWUDs, especially people who inject drugs (PWIDs) who share syringes and needles with multiple partners or have unprotected sex contribute considerably to a higher HIV prevalence. Non-injecting drug users are at a higher risk of experiencing physical and mental health problems [8] and poly-substance abuse disorder. They also may become injecting drug users with an increased risk of HIV infection [9-11]. The 2012 estimate of the size of this key population, conducted by the National Center for HIV/ AIDS, Dermatology and STIs (NCHADS), suggested that there were approximately 28,000 PWUDs in Cambodia; half of them were ATS users, and close to $7 \%$ reported injecting heroin [12].

In Asia, the HIV prevalence among PWIDs varies from country to country and within countries. For example, the HIV prevalence among PWIDs was $36.4 \%$ in Indonesia (2011), 25.2\% in Thailand, $16.6 \%$ in Malaysia, $10.5 \%$ in Vietnam, and $6.4 \%$ in China $[13,14]$. Factors that may account for this variability between countries include the intensity of harm reduction programs, overlapping risk behaviors (e.g. interaction with paid sex, and having multiple sex partners) and drug injection and social and sexual networking $[15,16]$.

In the past, studies have indicated that factors associated with the HIV prevalence among PWIDs include socio-demographic characteristics (e.g., sex, older age, marital status, less education), risky sexual behaviors (e.g., paid sex, sex exchanged for drugs) and risky behaviors during drug use (e.g., needle and syringe sharing, using injected drugs for more than one year) $[14,17,18]$.

In Cambodia, there have been a few studies on drug use policy and harm reduction intervention programs, such as needle and syringe distribution programs $[19,20]$. For example, Chheng et al indicated that in 2003, the Government of Cambodia acknowledged the importance and necessity of harm reduction approaches to prevent HIV transmission among PWUDs and their sexual partners. However, the harm reduction intervention was never fully implemented due to limited awareness and support from law enforcement at the local level as well as budgeting commitment [19]. The failure of this policy indeed had a negative impact on HIV prevention and harm reduction for the highest-risk groups, such as PWUDs.

Little is known about the characteristics and patterns of drug use in Cambodia. Moreover, the HIV prevalence among this key population has never been estimated nationwide. Therefore, this paper, which used data from a study conducted in late 2012-2013 [12], sought to estimate the prevalence of HIV infection among people who inject drugs (PWIDs) and drug users who do not inject drugs (non-PWIDs), and examine factors associated with HIV infection in these populations.

\section{Methods}

\section{Study sites and population}

Nine provinces were purposively selected for the study: Phnom Penh, Sihanoukville, Kampong Speu, Battambang, Banteay Meanchey, Siem Reap, Kampong Cham, Prey Veng, and Svay Rieng. These provinces were selected based on a program report indicating that they accounted for $85 \%$ of all PWUDs in Cambodia and that drug abuse activity in these provinces was significantly high (Consultative Technical Working Group on Drug and HIVAIDS, 2012). Study participants were individuals at least 15 years old who reported using any illicit drug, including heroin, cocaine, opiates, amphetamines, methamphetamines, yama, ice, crystal and ketamine, in the past 12 months.

In the analysis, the 9 provinces were separated into two groups based on the HIV prevalence among PWUDs: those with an HIV prevalence $\geq 4 \%$ were assigned to the high-risk province group (Sihanoukville, Phnom Penh, Battambang, and Banteay Meanchey), and those with a lower prevalence were assigned to the low-risk province group (Kampong Speu, Kampong Cham, Prey Veng, Svay Rieng and Siem Reap).

\section{Sampling and sample size}

We used respondent-driven sampling (RDS), a network referral method, to recruit this hard-to-reach population (PWUDs) to ensure a representative sample [21]. At the beginning, 36 diverse seeds (4 seeds per province) were recruited through local NGOs working with drug users. They were selected based on sex (male/female) and type of drug use (injecting/non-injecting). Each seed was asked to recruit other 2 eligible PWUDs from their personal network using study coupons, with the aim of having 4 or 5 waves of recruitment to reach equilibrium [21]. In total, we approached 1662 participants. However, 36 of the 1662 (2.2\%) were not eligible after the initial screening process, resulting in the final sample size of 1626.

\section{Data collection: Risk behaviors and blood specimens}

The data collection was conducted from August 2012 to April 2013. Recruitment sites in each province were selected based on the information from provincial HIV/drug programs that worked with the drug users and were aware of places commonly accessible to PWUDs. The main criterion for recruitment sites was that they provide a space to ensure the privacy and confidentiality of the participants. After oral informed consent was received from the participants, the interviews were conducted by gender-matched interviewers (e.g., male interviewers interviewed male participants) and were followed by a request for a blood sample. The interviewers used a questionnaire to collect data on socio-demographic characteristics, drug-taking behaviors, types and frequency of drug use and HIV-related risk 
behaviors. The questionnaire was based on a small-scale survey of drug users in Cambodia in 2006 and on pre-testing [22]. The interviews lasted approximately $30 \mathrm{~min}$.

A 5-ml blood sample was drawn and kept in a tube with an anti-coagulant to prevent the blood from clotting. At the end of each day, the blood samples were sent to a laboratory at a Voluntary Counseling and Testing Center (VCT) near the study recruitment site.

\section{Monitoring and HIV testing and quality control}

The interviewers and supervisors were selected from among those who had experience working with these key populations. Both the interviewers and supervisors were trained for 3 days in Phnom Penh on the recruitment process, informed consent procedures and the questionnaire-based interview procedure. The supervisors were responsible for ensuring that RDS sampling was properly performed, the questionnaires were properly completed, and the informed consent process was strictly followed to ensure that the participants could refuse or withdraw from the study at any time.

At VCT, HIV testing was performed using 2 rapid tests. First, blood samples were tested with Determine HIV 1/2 (Alere HIV). Specimens that were reactive in the first test were retested with HIV 1/2 Stat-Pak (Chembio Diagnostic System, Inc). This standard serial testing algorithm has been used by the national HSS for groups that have an HIV prevalence greater than 10\% [2]. Then, the sera were prepared and stored before being sent to the NCHADS laboratory for quality control and storage.

All HIV-positive specimens plus a randomly selected $10 \%$ of negative specimens were tested for quality control. Serial testing was performed by the NCHADS laboratory using two ELISA tests (Vironostika, BioMérieu; and Murex 1.2.0, Murex DiaSorin Biotech). The Vironostika test was used first. If the result was non-reactive, the test was considered HIV negative. If the Vironostika test was reactive, the results were confirmed via the Murex test.

\section{Statistical analysis}

HIV prevalence estimates were calculated using the RDS analysis tool RDSAT 7.1 [23]. RDSAT was developed to minimize biases associated with the social network referral process by weighting the respondents' probability of being recruited into the RDS sample and recruitment patterns [21]. Individual weights generated with RDSAT for HIV status were imported into STATA to adjust for the RDS sampling process [24]. Weighted bivariable analysis and multivariate logistic regression (SVY) were used to identify factors associated with HIV prevalence. Potential confounding factors, regardless their significant level, and factors that were associated with HIV infection in the bivariable analysis at $p<0.20$ [25] were included in the multivariate logistic regression; the included factors were sex, age group, provincial region, marital status, education level, drug use type, number of paid sex partners, and duration of drug use.

\section{Results}

\section{Demographic characteristics of PWUDs}

Of the 1626 respondents, approximately $7.3 \%$ were PWIDs. Most of the PWUDs were men (82.0\%), while women represented approximately $18.0 \%$. The median age of the PWIDs was 28.0 years, with an interquartile range (IQR) of 24-32 years; the median age for the non-PWIDs was 24.0 years (IQR: 20-29 years). For both groups, the women were approximately $2-3$ years older, and the PWIDs tended to be slightly older than the non-PWIDs (Table 1). Approximately half of the participants were un-married (i.e., single, widowed, or divorced). The median number of years of schooling was 6.0 (IQR: 3-8 years) for the PWIDs and 7.0 (IQR: 59 years) for the non-PWIDs. More than $40 \%$ of the PWIDs reported either living with their parents or spouse, while close to $75 \%$ of the non-PWIDs reported similar living arrangements. The PWID group was more likely to live with friends ( $15.3 \%$ vs. $7.8 \%)$.

\section{Drug use behavior among PWUDs}

The median duration of drug use for the PWIDs was 10.0 years (IQR: $5-13$ years), compared with 4.0 years (IQR: 1-7 years) for the non-PWIDs (Table 2). Less than $20 \%$ of the PWIDs first started using drugs by injection; the rest mainly began by smoking and sniffing drugs. Both groups (91\%) reported first starting drug use with friends and peers. Frequently, they were first introduced to drugs by their friends (85.9\%), followed by self-initiation $(8.5$ and $6.6 \%$ for PWIDs and non-PWIDs, respectively). The drugs that the PWIDs most commonly reported using in the past 12 months were ice/amphetamine $(78.0 \%)$ and heroin $(61.9 \%)$, while the non-PWIDs reported using ice/amphetamine (81.5\%) and yama (47.1\%), a pill containing methamphetamine. Moreover, close to 60 and $38 \%$ of the PWIDs and non-PWIDs, respectively, reported having used at least 2 drugs in the past 12 months. In addition, 35.6\% the PWIDs reported having shared needles and syringes in the past month.

\section{Sexual behavior among PWUDs}

More PWIDs (94.1\%) had had sex in their lifetimes than non-PWIDs (89.7\%). The women in both groups reported more sexual activity than the men (Table 3). Among those who had ever had sex in their lifetime, approximately three-quarters of both groups reported "being paid and paying for sex" in the past month. The women reported a higher proportion of paid sex 
Table 1 Socio-demographic characteristics of PWUD

\begin{tabular}{|c|c|c|c|c|c|c|c|c|c|c|c|c|}
\hline \multirow[t]{3}{*}{ Variables } & \multicolumn{6}{|c|}{ PWID = 119} & \multicolumn{6}{|c|}{ Non PWID = 1507} \\
\hline & \multicolumn{2}{|l|}{ Men } & \multicolumn{2}{|c|}{ Women } & \multicolumn{2}{|l|}{ Total } & \multicolumn{2}{|l|}{ Men } & \multicolumn{2}{|c|}{ Women } & \multicolumn{2}{|l|}{ Total } \\
\hline & Freq. & $\%$ & Freq. & $\%$ & Freq. & $\%$ & Freq. & $\%$ & Freq. & $\%$ & Freq. & $\%$ \\
\hline \multicolumn{13}{|l|}{ Regional provinces ${ }^{a}$} \\
\hline Low risk provinces & 23 & 22.3 & 2 & 12.5 & 25 & 21.0 & 745 & 61.9 & 73 & 26.8 & 818 & 55.4 \\
\hline High risk provinces & 80 & 77.7 & 14 & 87.5 & 94 & 79.0 & 459 & 38.1 & 199 & 73.2 & 658 & 44.6 \\
\hline Age, median $(\mathrm{IQR})^{\mathrm{b}}$, years & \multicolumn{2}{|c|}{$28(24-31)$} & \multicolumn{2}{|c|}{$30(26-34)$} & \multicolumn{2}{|c|}{$28(24-32)$} & \multicolumn{2}{|c|}{$23(20-28)$} & \multicolumn{2}{|c|}{$27(22-31)$} & \multicolumn{2}{|c|}{$24(20-29)$} \\
\hline \multicolumn{13}{|l|}{ Age groups } \\
\hline$\leq 20$ years old & 12 & 12.1 & 1 & 6.3 & 13 & 11.3 & 351 & 29.6 & 46 & 17.2 & 397 & 27.3 \\
\hline $21-29$ years old & 50 & 50.5 & 6 & 37.5 & 56 & 48.7 & 594 & 50.1 & 138 & 51.7 & 732 & 50.4 \\
\hline$\geq 30$ years old & 37 & 37.4 & 9 & 59.2 & 46 & 40.0 & 240 & 20.3 & 83 & 31.1 & 323 & 22.3 \\
\hline \multicolumn{13}{|l|}{ Marital status } \\
\hline Married & 48 & 47.1 & 14 & 87.5 & 62 & 52.5 & 472 & 39.5 & 225 & 83.0 & 697 & 47.5 \\
\hline Non-married & 54 & 52.9 & 2 & 12.5 & 56 & 47.5 & 723 & 60.5 & 46 & 17.0 & 769 & 52.5 \\
\hline Education, median (IQR), years & \multicolumn{2}{|c|}{$7(3-9)$} & \multicolumn{2}{|c|}{$3(1-6)$} & \multicolumn{2}{|c|}{$6(3-8)$} & \multicolumn{2}{|c|}{$8(6-10)$} & \multicolumn{2}{|c|}{$4(0-7)$} & \multicolumn{2}{|c|}{$7(5-9)$} \\
\hline \multicolumn{13}{|l|}{ Education level } \\
\hline $0-6$ years in school & 49 & 50.0 & 3 & 18.7 & 62 & 54.4 & 745 & 65.3 & 71 & 26.8 & 591 & 42.0 \\
\hline$\geq 7$ years in school & 49 & 50.0 & 13 & 81.3 & 52 & 45.6 & 397 & 34.7 & 194 & 73.2 & 816 & 58.0 \\
\hline \multicolumn{13}{|l|}{ Report current living places } \\
\hline Parent & 36 & 35.3 & 1 & 6.2 & 36 & 30.5 & 708 & 59.3 & 42 & 15.5 & 763 & 51.0 \\
\hline Spouse & 15 & 14.7 & 4 & 25.0 & 19 & 16.0 & 272 & 22.8 & 56 & 20.7 & 332 & 22.2 \\
\hline Friend & 15 & 14.7 & 4 & 25.0 & 18 & 15.3 & 60 & 5.0 & 54 & 19.9 & 117 & 7.8 \\
\hline Street & 5 & 4.9 & 0 & 0.0 & 5 & 4.3 & 15 & 1.3 & 20 & 7.4 & 38 & 2.5 \\
\hline Others & 31 & 30.4 & 7 & 43.8 & 40 & 33.9 & 139 & 11.4 & 99 & 36.5 & 245 & 16.5 \\
\hline
\end{tabular}

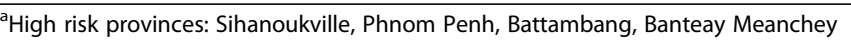

Low risk provinces: Kampong Speu, Kampong Cham, Prey Veng, Svay Rieng, Siem Reap

bIQR interquartile range

than the men among both the PWIDs $(85.8 \%)$ and the non-PWIDs (89.4\%). However, reports of always using condoms during paid sex did not exceed $50 \%$ among the PWIDs but were greater than $60 \%$ among non-PWIDs. Condom use among the women in the PWID group was as low as $25 \%$. In addition, reports of condom use with regular partners (spouses, intimate partners, cohabiting partners) was as low as $\leq 30 \%$ in both groups.

\section{HIV prevalence among PWUDs}

As shown in Table 4, the overall HIV prevalence among PWUDs was 5.1\% [95\% CI: 4.1-6.2]. The HIV prevalence among PWIDs was $24.8 \%$ [95\% CI: 7.339.9]; among non-PWIDs, it was $4.0 \%$ [95\% CI: $2.7-$ 5.5]. The HIV prevalence among female PWIDs (37.5, 95\% CI: 10.9-64.1) was higher than that among male PWIDs (22.5\%, 95 CI: 14.0-30.9). A similar pattern was found among female non-PWIDs $(11.5,95 \% \mathrm{CI}$ : 7.9-15.7) and male non-PWIDs (1.5, 95\% CI: 0.82.2).
Factors associated with HIV infection in the logistic regression The details of the bivariate analysis are presented in Table 5. The following factors were significantly associated with HIV: higher-risk province group [odds ratio $(\mathrm{OR})=5.2$, 95\% CI: 2.6-10.5] (with the lower-risk province group used as the referent group); female (males as the reference) $(\mathrm{OR}=5.6,95 \% \mathrm{CI}: 3.0-10.6)$; and older age groups (aged $\leq 20$ years as the reference) $21-29$ (OR $=21.2), 30$ and older $(\mathrm{OR}=78.5)$. Low education level (secondary/higher education as the reference) and married PWUDs (non-married as the reference) were associated with HIV infection. The PWIDs had approximately 5 times higher odds of HIV infection than the non-PWIDs (OR $=4.6,95 \% \mathrm{CI}: 2.3-9.2)$. Furthermore, having had $\geq 2$ paid sex partners in the past month and having used drugs for $\geq 12$ months were significantly associated with HIV infection, with $\mathrm{OR}=3.5$ (95\% CI: 1.6-7.5) and $\mathrm{OR}=2.7$ (95\% CI: 1.3-5.6), respectively. The associations for other covariates, including reported consistent condom use with paid sex partners in the past 12 months and multiple drug use, were not statistically significant. 
Table 2 Drug taking risk exposures among PWUDs

\begin{tabular}{|c|c|c|c|c|c|c|c|c|c|c|c|c|}
\hline \multirow[t]{3}{*}{ Variables } & \multicolumn{6}{|c|}{$P W I D=119$} & \multicolumn{6}{|c|}{ Non- PWID = 1506} \\
\hline & \multicolumn{2}{|c|}{$\overline{M e n}$} & \multicolumn{2}{|c|}{ Women } & \multicolumn{2}{|c|}{ Total } & \multicolumn{2}{|l|}{$\overline{\text { Men }}$} & \multicolumn{2}{|c|}{ Women } & \multicolumn{2}{|l|}{ Total } \\
\hline & Frec & $\%$ & Freq. & $\%$ & Freq. & $\%$ & Freq. & $\%$ & Freq. & $\%$ & Freq. & $\%$ \\
\hline Duration of drug use, median (IQR) & \multicolumn{2}{|c|}{$10(5-13)$} & \multicolumn{2}{|c|}{$10(4-12)$} & \multicolumn{2}{|c|}{$10(5-13)$} & \multicolumn{2}{|c|}{$4(1-8)$} & \multicolumn{2}{|c|}{$3(1-6)$} & \multicolumn{2}{|c|}{$4(1-7)$} \\
\hline \multicolumn{5}{|l|}{ Duration of any drug use } & \multicolumn{2}{|c|}{$n=117$} & & & & & \multicolumn{2}{|c|}{$n=1468$} \\
\hline Users $\leq 12$ months & 7 & 6.9 & 3 & 20.0 & 10 & 8.6 & 303 & 25.2 & 82 & 30.7 & 385 & 26.2 \\
\hline Users > 12 months & 95 & 93.1 & 12 & 80.0 & 107 & 91.4 & 898 & 74.8 & 185 & 69.3 & 1083 & 73.8 \\
\hline \multicolumn{13}{|l|}{ Methods PWUDs used drugs at the first time } \\
\hline Smoking & 74 & 72.6 & 14 & 82.5 & 87 & 73.7 & 1158 & 96.7 & 254 & 93.7 & 1440 & 96.1 \\
\hline Sniffing/drinking & 8 & 7.8 & 0 & 0 & 8 & 6.9 & 35 & 2.9 & 15 & 5.5 & 52 & 3.5 \\
\hline Injecting & 20 & 19.6 & 2 & 12.5 & 22 & 18.6 & 4 & 0.3 & 2 & 0.7 & 6 & 0.4 \\
\hline \multicolumn{13}{|l|}{ Persons PWUDs used drug with at the first time } \\
\hline Friends & 89 & 87.4 & 13 & 81.3 & 103 & 87.3 & 1141 & 95.2 & 202 & 74.5 & 1370 & 91.3 \\
\hline Sweethearts/spouses/relatives & 8 & 7.8 & 2 & 12.5 & 10 & 8.4 & 26 & 2.2 & 47 & 17.3 & 73 & 4.9 \\
\hline Alone & 4 & 3.9 & 0 & 0.0 & 4 & 3.4 & 29 & 2.1 & 14 & 5.2 & 43 & 2.9 \\
\hline Others & 1 & 0.9 & 1 & 6.2 & 1 & 0.9 & 3 & 0.3 & 8 & 3.0 & 15 & 0.9 \\
\hline \multicolumn{13}{|l|}{ Persons who first introduced you to use drugs } \\
\hline Friends & 85 & 83.3 & 12 & 75.0 & 98 & 83.0 & 1079 & 90.0 & 189 & 69.7 & 1292 & 86.1 \\
\hline Myself & 8 & 7.8 & 2 & 12.5 & 10 & 8.5 & 73 & 6.1 & 22 & 8.1 & 99 & 6.5 \\
\hline Sweethearts/spouses/relatives & 8 & 7.8 & 2 & 12.5 & 10 & 8.5 & 44 & 3.7 & 49 & 18.1 & 76 & 5.1 \\
\hline Others & 1 & 1.0 & 0 & 0.0 & 0 & 0.0 & 3 & 0.2 & 11 & 4.1 & 34 & 2.3 \\
\hline \multicolumn{13}{|l|}{ Types of illicit drug used in the past 12 months } \\
\hline Ice/amphetamine & 79 & 77.5 & 14 & 87.5 & 92 & 78.0 & 998 & 82.9 & 203 & 74.6 & 1228 & 81.5 \\
\hline Yama (pill of methamphetamine) & 30 & 29.4 & 7 & 43.8 & 37 & 31.4 & 557 & 46.3 & 148 & 54.4 & 710 & 47.1 \\
\hline Marijuana & 16 & 15.7 & 1 & 6.3 & 17 & 14.4 & 140 & 11.6 & 13 & 4.8 & 153 & 10.2 \\
\hline Heroin & 59 & 57.8 & 12 & 75.0 & 73 & 61.9 & 33 & 2.7 & 9 & 3.3 & 42 & 2.8 \\
\hline Ecstasy & 4 & 3.9 & 3 & 18.8 & 7 & 5.9 & 54 & 4.5 & 26 & 9.6 & 80 & 5.3 \\
\hline Others (including inhalant) & 13 & 8.1 & 1 & 1.5 & 19 & 16.1 & 149 & 12.4 & 17 & 6.3 & 136 & 5.3 \\
\hline Reported uses at least 2 drugs in past 12 months & 58 & 56.8 & 12 & 75.0 & 70 & 59.3 & 455 & 37.9 & 107 & 39.4 & 562 & 38.1 \\
\hline Last injecting drugs with re-used syringes and needles $(n=119)$ & - & - & - & - & 38 & 31.9 & - & - & - & - & - & - \\
\hline $\begin{array}{l}\text { Reported sharing needles and syringes when injecting drugs in past } \\
\text { month }(n=59)\end{array}$ & - & - & - & - & 21 & 35.6 & - & - & - & - & - & - \\
\hline
\end{tabular}

In the final multivariable model, 4 factors were found to be independently associated with HIV infection: sex (women), older age groups, injected drug use and duration of drug use $\geq 12$ months (Table 5). Women had higher odds of HIV infection than men, with an adjusted $\mathrm{OR}(\mathrm{AOR}=7.8,95 \% \mathrm{CI}$ : 3.0-20.4), and participants older than 20 years had a higher odds of HIV infection: age groups $21-29$ (AOR $=10.3$, 95\% CI: $1.2-20.4$ ) and age group $\geq 30$ (AOR $=36.4$, 95\% CI: 3.6-369.4). Injected drug use remained a strong predictor of $\mathrm{HIV}$ infection, with $\mathrm{AOR}=4.1$ (95\% CI: 1.5-10.9). Additionally, the longer a PWUD had used drugs, the higher their odds of HIV infection, with $\mathrm{AOR}=4.0$ (95\% CI: 1.4-11.4).

\section{Discussion}

This study reported a high prevalence of HIV among PWIDs and a large proportion of non-PWIDs, especially ATS users. Most of the PWUDs were sexually active, and they indicated a high proportion of paid sex and low consistent condom use, especially among PWIDs. The main predictors of HIV infection included female sex, injected drug use, older age and drug use for $\geq 12$ months.

In our study, the HIV prevalence among PWIDs was approximately $25 \%$, which is similar to the prevalence levels for Cambodia reported a few years ago by Mathers et al., who reviewed and estimated the global HIV prevalence among drug users and the size of the 
Table 3 Sexual risk exposures to HIV among PWUDs

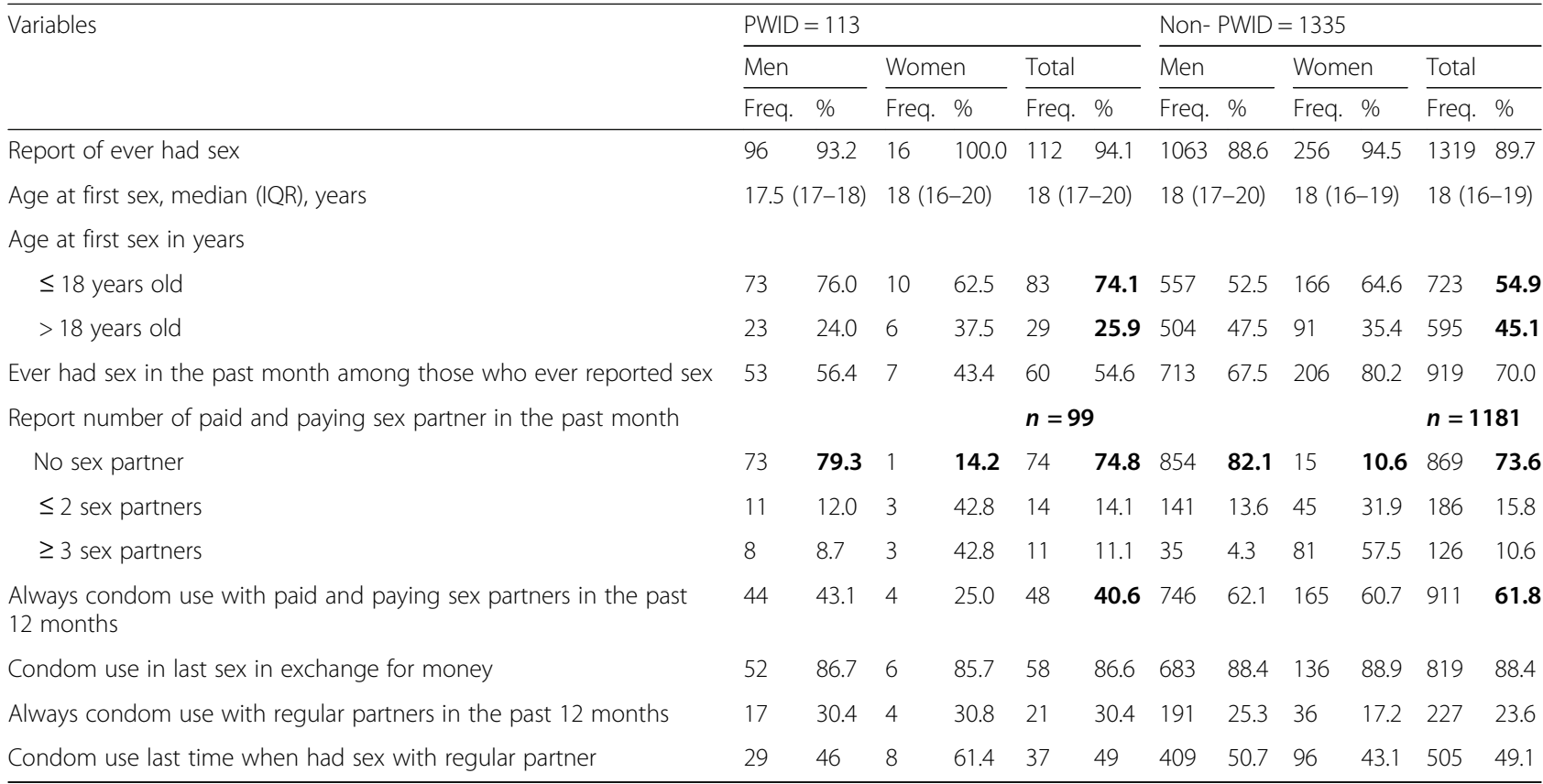

HIV-infected drug user population and injecting drug user population by country [26].

Despite the lower prevalence of HIV (4\%) among non-PWIDs, the large non-PWUDs population (90\%) remains a public health and a matter of social concern for several reasons. First, recent reports may indicate shifting patterns of HIV infection in Cambodia from non-PWIDs to PWIDs. Our findings indicated that less than $20 \%$ of PWIDs initially injected drugs. Additionally, a report from the KHANA Drop-In Center (DiC) showed that less than 5\% of PWUDs who visited the center were originally injected drug users. However, in one year of the $\mathrm{DiC}$ implementation, approximately $3 \%$ of its visitors converted from non-PWIDs to PWIDs (Personal communication with DiC).Therefore, these raise a concern what prompts PWUDs to become PWIDs and the possibility that that HIV transmission among non-PWIDs in Cambodia could increase in the future due to their related risk behaviors and the overlapping social and sexual networks among PWUDs $[16,27]$. Additionally, the high proportion of transactional sex among female PWUDs in this study, particularly among non-PWID women, indicates the possibility that infection could be transmitted to non-injected drug users and then to the general population through transactional sex. Consequently, these factors potentially contribute to an increase in overall HIV prevalence in Cambodia. Therefore, it is important for HIV and drug use intervention programs to significantly target these high-risk groups.

Needle and syringe sharing among PWIDs remains high, and implements are often shared with little or no cleaning. Given that sterile needle and syringes programs (NSPs) are a key component of harm reduction and HIV prevention efforts [15, 28-30], more targeted interventions for PWIDs should be implemented continuously, without law enforcement barriers, to ensure access to adequate supplies of clean needles and syringes. Prior studies estimated that interventions (i.e., opioid substitution, needle exchange and antiretroviral therapy) that attain at least $60 \%$ coverage could cut future infections among PWIDs roughly in half, thereby decreasing the HIV epidemic among PWIDs [28]. However, the program report suggested that NSPs had very low coverage - only 16\% of PWIDs reported accessing NGO drop in centers in the past 12 months [31]. Further research should include NSP assessments to improve program interventions. Additionally, the large proportion of

Table 4 HIV prevalence among PWUDs

\begin{tabular}{|c|c|c|c|c|c|}
\hline \multicolumn{3}{|l|}{ PWID } & \multicolumn{3}{|l|}{ Non-PWID } \\
\hline Men & Women & Total & Men & Women & Total \\
\hline$\%(95 \% \mathrm{Cl})$ & $\%(95 \%$ Cl) & $\%(95 \%$ Cl) & $\%(95 \% \mathrm{Cl})$ & $\%(95 \%$ Cl) & $\%(95 \% \mathrm{Cl})$ \\
\hline 22.5 (14.0-30.9) & 37.5 (10.9-64.1) & $24.8(7.3-39.9)$ & $1.5(0.8-2.2)$ & $11.5(7.9-15.7)$ & $4.0(2.7-5.5)$ \\
\hline
\end{tabular}


Table 5 Risk factors associated with HIV in bivariate and multivariable logistic regression among drug users

\begin{tabular}{|c|c|c|c|c|}
\hline \multirow[t]{2}{*}{ Variables } & \multicolumn{2}{|l|}{$N=1583$} & \multicolumn{2}{|c|}{ Total sample $(N=1186)$} \\
\hline & $\mathrm{OR}(95 \% \mathrm{Cl})$ & $P$ value ${ }^{b}$ & $\overline{\operatorname{AOR}^{a}(95 \% C l)}$ & $P$ value ${ }^{b}$ \\
\hline \multicolumn{5}{|l|}{ Provincial group ${ }^{\mathrm{a}}$} \\
\hline Low risk provinces & Referent & & Referent & \\
\hline High risk provinces & $5.2(2.59-10.56)$ & $<0.001$ & $1.9(0.78-4.79)$ & 0.154 \\
\hline \multicolumn{5}{|l|}{ Sex of drug users } \\
\hline Men & Referent & & Referent & \\
\hline Women & $5.6(2.95-10.59)$ & $<0.001$ & $7.8(3.00-20.35)$ & $<0.001$ \\
\hline \multicolumn{5}{|l|}{ Age group in years } \\
\hline$\leq 20$ & Referent & & Referent & \\
\hline $21-29$ & $21.2(2.73-164.16)$ & 0.003 & $10.3(1.20-89.39)$ & 0.033 \\
\hline$\geq 30$ & 78.5 (10.53-584. 18) & $<0.001$ & $36.4(3.59-369.36)$ & 0.002 \\
\hline \multicolumn{5}{|l|}{ Marital status } \\
\hline Non-married & Referent & & Referent & \\
\hline Married & $2.9(1.37-6.01)$ & 0.005 & $0.48(0.17-1.47)$ & 0.205 \\
\hline \multicolumn{5}{|l|}{ Education level } \\
\hline$\leq 6$ years (Primary) & $2.4(1.22-4.68)$ & 0.011 & $0.92(0.37-2.27)$ & 0.866 \\
\hline$>6$ years (Secondary and higher) & Referent & & Referent & \\
\hline \multicolumn{5}{|l|}{ Drug use type } \\
\hline Non-PWID & Referent & & Referent & \\
\hline PWID & $4.6(2.31-9.19)$ & $<0.001$ & $4.1(1.53-10.96)$ & 0.005 \\
\hline \multicolumn{5}{|c|}{ Number of paid and paying sex partners In past month } \\
\hline$<2$ partners & Referent & & Referent & \\
\hline$\geq 2$ partners & $3.5(1.64-7.48)$ & 0.001 & $1.1(0.42-2.47)$ & 0.961 \\
\hline \multicolumn{5}{|l|}{ Duration of using drugs } \\
\hline$\leq 12$ months & Referent & & Referent & \\
\hline$>12$ months & $2.7(1.27-5.63)$ & 0.010 & $4.0(1.38-11.35)$ & 0.010 \\
\hline \multirow{2}{*}{\multicolumn{5}{|c|}{$\begin{array}{l}\text { Consistent condom use with casual } \\
\text { partner in the past } 12 \text { months }\end{array}$}} \\
\hline & & & & \\
\hline Yes & Referent & & & \\
\hline No & $1.1(0.59-2.10)$ & 0.735 & - & - \\
\hline \multicolumn{5}{|c|}{ More than one drug use in past 12 months } \\
\hline One drug & Referent & & & \\
\hline More than one drug & $1.1(0.59-2.10)$ & 0.735 & - & - \\
\hline
\end{tabular}

${ }^{\mathrm{a} H i g h}$ risk provinces: Sihanoukville, Phnom Penh, Battambang, Banteay Meanchey

${ }^{\mathrm{b}}$ The results in this table were weighted

Low risk provinces: Kampong Speu, Kampong Cham, Prey Veng, Svay Rieng, Siem Reap

non-PWIDs, especially ATS users, is worrisome and very challenging for prevention efforts since effective prevention strategies for ATS use has little evidence base. A study of an integrated HIV and drug prevention program with conditional cash transfer was conducted in Cambodia to test the use of behavioral interventions among ATS users for improved prevention measures for this group; the results have not been published [32]. However, another formative research among study by Carrico et al. to reduce the risk of ATS among entertainment workers using the conditional cash transfer with behavioral intervention found the mixing results [33].

The findings of a higher risk of HIV among women who use drugs are consistent with the literature, which highlights issues associated with increased vulnerability for women (e.g., child care, concomitant sex work, lack of access to health care, mental and physical health problems, reproductive health issues, sexually transmitted infections, stigma, and violence) $[8,30]$. Beyond these issues, female PWUDs with overlapping risk behaviors, such as 
transactional sex and drug use, often have less power to negotiate safe sex practices $[8,17,34]$. According to Azim et al., female PWUDs who were sex workers were more likely than non-drug using sex workers to engage in street-based sex work, which is associated with high-risk sex and heightened levels of violence due to different types of partners [30].

Given the high HIV prevalence among drug users with a high frequency of paid sex partners, focused intervention to assist this sub-group is an important public health goal in Cambodia. Evidence in prior studies suggests that female PWIDs who are sex workers constitute a "bridge population" [35] that can lead to a the spread of HIV epidemics from PWIDs to heterosexual populations [30, 36].

Multiple structural and behavioral interventions specifically designed for female PWUDs have been implemented globally with tailor-made interventions adapted to women's specific needs [30]. For example, a study investigating the effectiveness of HIV/STI safer sex skill-building groups for women found that these groups improved safer sex practices compared with standard HIV/STI education [37]. However, many women still struggle alone to change risky behaviors with their partners, and in these situations, it may be more effective to engage couples in harm reduction interventions [30]. Also, access to legal and heath care supports should be addressed in the multiple structural interventions.

Comprehensive interventions that address individual and socio-environmental factors are more effective than a single intervention alone [29]. Such interventions need to include many of the interventions outlined above and should also outline steps for improving understanding and sensitivity among professionals who interact with PWUDs (e.g., health care workers or NGO staff) [30]. This is particularly the case with law enforcement. As a recent study surmised, "Fear of accessing harm reduction and health services and police's negative attitudes and practices towards key populations present major barriers to HIV prevention efforts in Cambodia" [19, 38]. Efforts to reduce the fear of retaliation and/or stigma may help improve the effectiveness of broader intervention programs.

This study has several limitations. First, self-reports of sensitive information (i.e., drug use and risky sexual behaviors) and social desirability may result in the under-reporting of actual information. Second, the lifetime and 12-month recalls used in some questions may have caused recall issues. Third, although RDS was used to recruit a representative sample, we are not sure how well the seeds were represented and referred or how many PWUDs did not participate in the study (mostly PWIDs, due to self-stigma or discrimination), and we do not know the different characteristics and HIV-related risk behaviors of those who did not participate in the study. Given these factors, we may have underestimated the HIV prevalence among PWIDs - especially female PWIDs, given the small samples - and weakened the association between the predictors and the HIV prevalence. Despite these limitations, this is the first ever large-scale survey conducted in Cambodia among PWUDs using the RDS method and involving many key stake- holders' involvement (NCHADS, NACD, UNAIDS, NGOs). It provides useful and informative findings to guide HIV and drug use program planning and policy for future interventions.

\section{Conclusion}

HIV prevalence among PWUDs remains high especially among PWIDs and women. Harm reduction programs, such as NSP, must be improved in scope and scale. Innovative strategies are needed to reach sub-groups of PWUDs, especially women who inject drugs. Furthermore, the large proportion of non-PWIDs, especially ATS users, should not be ignored; combined HIV prevention and harm reduction programs should integrate ATS users.

\section{Abbreviations \\ ART: Anti-retroviral therapy: ATS: Amphetamine-type stimulants (ATS); DiC: Drop-In Center; HSS: HIV Sentinel Surveillance; NACD: National Authority for Combating Drugs; NCHADS: National Center for HIV/AIDS, Dermatology and STIS; NSP: Needles and Syringes Program; PWIDs: People who inject drugs; PWUDs: People who use drugs; RDS: Respondent-driven sampling; VCT: HIV Voluntary Counseling and Testing Center}

\section{Acknowledgements}

We would like to thank the organizations that were actively involved in the study's Technical Advisory Group (TAG): NACD, NCHADS, the National Program for Mental Health, MoEYS, MoSVY, KHANA, AusAID, UNAIDS, PSI, UNODC, Friends Int'l- Mith Samlanh, FHI 360, UNICEF and WHO. Our sincere thanks go to H.E. Meas Vyrith, Secretary General of NACD; Dr. Mean Chhi Vun (Director of NCHADS); and Dr. Oum Sopheap, KHANA Executive Director, who helped to facilitate the administrative and financial processes of the study. Special thanks to the members of the TAG, who played significant roles in the completion of this work: Mr. Kao Boumony (NACD), Dr. Mun Phalkun (NCHADS), and Dr. Suos Premprey (AusAID). We would also like to thank the GF and AusAID for the financial support through NCHADS and KHANA, respectively.

\section{Funding}

The study was supported by the Global Fund through the National Center for HIV/AIDS, Dermatology and STIs (NCHADS) and AusAID through KHANA.

\section{Availability of data and materials}

The dataset supporting the conclusions of the article is available upon request from the corresponding author. Due to data protection restrictions and participant confidentiality, we cannot make participant data publicly available.

\section{Authors' contributions}

HS, CC and ST conceived and designed the study. JM contributed the conceptual ideas and drafted the paper and proofreading. HS wrote the first draft of the paper, and the other coauthors contributed to the final manuscript. HS and CC were responsible for conducting the study and managing the data. HS and CC conducted the statistical analyses and the interpretation of data. All authors read and approved the final manuscript.

\section{Ethics approval and consent to participate}

The study protocol and written informed consent form was approved by the National Ethics Committee for Health Research (NECHR), Cambodia (111-NECHR 2012). The purpose of the study was thoroughly explained to the study participants. Then, the written informed consent was obtained from all participants including those aged of 16. Privacy and confidentiality and the 
anonymity of the participants were ensured at all stages of data collection. Each participant's involvement in the study was voluntary. The participants were informed that if they wished to withdraw their participation, they could do so at any time without any restriction.

\section{Consent for publication}

Not applicable.

\section{Competing interests}

We declare that we have no competing interests.

\section{Publisher's Note}

Springer Nature remains neutral with regard to jurisdictional claims in published maps and institutional affiliations.

\section{Author details}

${ }^{1}$ School of Public Health at the National Institute of Public Health, Lot \#80, Samdech Penn Nouth Blvd. Tuol Kork District, Phnom Penh, Cambodia. ${ }^{2}$ Center for Population and Health Research, KHANA, Phnom Penh, Cambodia. ${ }^{3}$ Department of Epidemiology, University of Washington, Seattle, USA.

Received: 23 February 2017 Accepted: 31 October 2018

\section{Published online: 13 November 2018}

\section{References}

1. Chhea C, Saphonn V. Report on Estimation and Projections on HIV/AIDS in Cambodia 2010-2015. National Center for HIV/AIDS, Dermatology and STD: Phnom Penh; 2011.

2. Chhea C: HIV Sentinel Surveys 2010: Female Entertainment Workers (FEWs) and Antenatal Care Cinic (ANC) Attendees; Accessd on Febraury 20, 2016 at http:// www.nchads.org/Publication/HSS/HSS_2010\%20Report.pdf. In. Phnom Penh: National Center for HIV/AIDS, Dermatology and STIS (NCHADS); 2012.

3. Couture MC, Page K, Stein ES, Sansothy N, Sichan K, Kaldor J, Evans JL, Maher L Palefsky J. Cervical human papillomavirus infection among young women engaged in sex work in Phnom Penh, Cambodia: prevalence, genotypes, risk factors and association with HIV infection. BMC Infect Dis. 2012;12:166.

4. NCHADS: National HIV Sero-Surveillance among ANC and MSM 2014, acceed date on October 02, 2017 at http://www.nchads.org/index.php?id=16. In. Phnom Penh: National Center for HIVAIDS, Dermatology and STIs 2014.

5. NACD: Official report (in Khmer) of the National Achievement of drug control in 2015 and Workplan 2016, National Authority for combating drug (NACD). Accessed on on December 2016 at http://www.nacd.gov.kh/ images/nacd/Reports/annual/report_2015.pdf. In. Phnom Penh: NACD; 2016.

6. Klein A, Saphonn V, Reid S. Reaching out and reaching up - developing a low cost drug treatment system in Cambodia. Harm Reduct J. 2012;9:11.

7. MoEYS: Most at risk young people survey 2010. In. Phnom Penh: Ministry of Education, Youth and Sports; 2010.

8. Maher L, Phlong P, Mooney-Somers J, Keo S, Stein E, Couture MC, Page K. Amphetamine-type stimulant use and HIV/STI risk behaviour among young female sex workers in Phnom Penh, Cambodia. Int J Drug Policy. 2011;22(3): 203-9.

9. Degenhardt L, Mathers B, Guarinieri M, Panda S, Phillips B, Strathdee SA, Tyndall M, Wiessing L, Wodak A, Howard J. Meth/amphetamine use and associated HIV: implications for global policy and public health. Int J Drug Policy. 2010;21(5):347-58.

10. Colfax G, Santos GM, Chu P, Vittinghoff E, Pluddemann A, Kumar S, Hart C. Amphetamine-group substances and HIV. Lancet. 2010;376(9739):458-74.

11. Singh D, Chawarski MC, Schottenfeld R, Vicknasingam B. Substance abuse and the HIV situation in Malaysia. J Food Drug Anal. 2013;21(4):S46-51.

12. Chhea C, Sopheab H, Tuot S. National Population Size Estimation, HIV Related Risk Behaviors and HIV Prevalence among People Who Use Drugs in Cambodia in 2012. Phnom Penh: NACD, NCHADS, KHANA; 2014.

13. HIV and AIDS data hub for Asia-Pacific: Estimated size and HIV prevalence among people who inject drugs in Asia-Pacific; accessed on Jan 27, 2016 at http://www.aidsdatahub.org/people-who-inject-drugs-november-2015-slides

14. Li L, Assanangkornchai S, Duo L, McNeil E, Li J. Risk behaviors, prevalence of HIV and hepatitis C virus infection and population size of current injection drug users in a China-Myanmar border city: results from a respondentdriven sampling survey in 2012. PLoS One. 2014;9(9):e106899.
15. Mathers BM, Degenhardt L, Ali H, Wiessing L, Hickman M, Mattick RP, Myers B, Ambekar A, Strathdee SA. HIV prevention, treatment, and care services for people who inject drugs: a systematic review of global, regional, and national coverage. Lancet. 2010;375(9719):1014-28.

16. Strathdee SA, Stockman JK. Epidemiology of HIV among injecting and noninjecting drug users: current trends and implications for interventions. Curr HIV/AIDS Rep. 2010;7(2):99-106.

17. Taran YS, Johnston LG, Pohorila NB, Saliuk TO. Correlates of HIV risk among injecting drug users in sixteen Ukrainian cities. AIDS Behav. 2011;15(1):6574.

18. Medhi GK, Mahanta J, Paranjape RS, Adhikary R, Laskar N, Ngully P. Factors associated with HIV among female sex workers in a high HIV prevalent state of India. AIDS Care. 2012;24(3):369-76.

19. Chheng K, Leang S, Thomson N, Moore T, Crofts N. Harm reduction in Cambodia: a disconnect between policy and practice. Harm Reduct J. 2012; $9(1): 30$.

20. Thomson N, Leang S, Chheng K, Weissman A, Shaw G, Crofts N. The village/ commune safety policy and HIV prevention efforts among key affected populations in Cambodia: finding a balance. Harm Reduct J. 2012;9:31.

21. Heckathorn D. Respondent-driven sampling: a new approach to the study of hidden populations. Social Problem. 1997.

22. Chhea C, Seguy N: HIV prevalence among drug users in Cambodia 2007; accessed on Febraury 20, 2016 at www.nchads.org. In. Phnom Penh: NCHADS, NACD; 2010

23. Volz E, Wejnert C, Degani I, Heckathorn DD. Respondent-driven sampling analysis tool (RDSAT) version 7.1. Ithaca, NY: Cornell University; 2007. p. 2012.

24. Matthew S, Heckathorn D. Sampling and estimation in hidden populations using respondent-driven sampling. Sociol Methodol. 2004.

25. Hosmer D, Lemeshow S. Applied logistic regression. 2nd ed. New York: John Wiley \& Sons Inc; 2000.

26. Mathers BM, Degenhardt L, Phillips B, Wiessing L, Hickman M, Strathdee SA, Wodak A, Panda S, Tyndall M, Toufik A, et al. Global epidemiology of injecting drug use and HIV among people who inject drugs: a systematic review. Lancet. 2008;372(9651):1733-45.

27. Des Jarlais DC, Arasteh K, Perlis T, Hagan H, Abdul-Quader A, Heckathorn DD, McKnight C, Bramson H, Nemeth C, Torian LV, et al. Convergence of HIV seroprevalence among injecting and non-injecting drug users in new York City. AIDS. 2007;21(2):231-5.

28. Strathdee SA, Hallett TB, Bobrova N, Rhodes T, Booth R, Abdool R, Hankins CA. HIV and risk environment for injecting drug users: the past, present, and future. Lancet. 2010;376(9737):268-84.

29. Degenhardt L, Mathers B, Vickerman P, Rhodes T, Latkin C, Hickman M. Prevention of HIV infection for people who inject drugs: why individual, structural, and combination approaches are needed. Lancet. 2010;376(9737): 285-301.

30. Azim T, Bontell I, Strathdee SA. Women, drugs and HIV. Int J Drug Policy. 2015;26(Suppl 1):S16-21.

31. Sopheab H, Tuot S. End Project Evaluation: Changes in HIV Integrated, Prevention, Care and Impact Mitigation Efforts from 2009-2001. KHANA: Phnom Penh, Cambodia; 2012.

32. Page K, Stein ES, Carrico AW, Evans JL, Sokunny M, Nil E, Ngak S, Sophal C, McCulloch C, Maher L. Protocol of a cluster randomised stepped-wedge trial of behavioural interventions targeting amphetamine-type stimulant use and sexual risk among female entertainment and sex workers in Cambodia. BMJ Open. 2016;6(5):e010854.

33. Carrico AW, Nil E, Sophal C, Stein E, Sokunny M, Yuthea N, Evans JL, Ngak S, Maher L, Page K. Behavioral interventions for Cambodian female entertainment and sex workers who use amphetamine-type stimulants. J Behav Med. 2016;39(3):502-10.

34. Bouscaillou J, Evanno J, Proute M, Inwoley A, Kabran M, N'Guessan T, Dje-Bi S, Sidibe S, Thiam-Niangoin M, N'Guessan BR, et al. Prevalence and risk factors associated with HIV and tuberculosis in people who use drugs in Abidjan, Ivory Coast. Int J Drug Policy. 2016;30:116-23.

35. Liu H, Grusky O, Li X, Ma E. Drug users: a potentially important bridge population in the transmission of sexually transmitted diseases, including AIDS, in China. Sexually transmitted diseases. 2006;33(2):111-7.

36. Des Jarlais DC, Feelemyer JP, Modi SN, Arasteh K, Mathers BM, Degenhardt $L$, Hagan H. Transitions from injection-drug-use-concentrated to selfsustaining heterosexual HIV epidemics: patterns in the international data. PLoS One. 2012;7(3):e31227. 
37. Tross S, Campbell AN, Cohen LR, Calsyn D, Pavlicova M, Miele GM, Hu MC, Haynes L, Nugent N, Gan W, et al. Effectiveness of HIV/STD sexual risk reduction groups for women in substance abuse treatment programs: results of NIDA clinical trials network trial. J Acquir Immune Defic Syndr. 2008:48(5):581-9.

38. Schneiders ML, Weissman A. Determining barriers to creating an enabling environment in Cambodia: results from a baseline study with key populations and police. J Int AIDS Soc. 2016;19(4 Suppl 3):20878.

- fast, convenient online submission

- thorough peer review by experienced researchers in your field

- rapid publication on acceptance

- support for research data, including large and complex data types

- gold Open Access which fosters wider collaboration and increased citations

- maximum visibility for your research: over $100 \mathrm{M}$ website views per year

At BMC, research is always in progress.

Learn more biomedcentral.com/submissions 